\title{
Mechanism of Solder Joint Cracks in Anisotropic Conductive Films Bonding and Solutions: Delaying Hot-Bar Lift-Up Time and Adding Silica Fillers
}

\author{
Shuye Zhang ${ }^{1, *}$, Ming Yang ${ }^{2}$, Mingliang Jin ${ }^{3,4}$, Wen-Can Huang ${ }^{3}$, Tiesong Lin ${ }^{1}$, Peng He ${ }^{1}$, \\ Panpan Lin ${ }^{1}$ and Kyung-Wook Paik ${ }^{5}$ \\ 1 State Key Laboratory of Advanced Welding and Joining, Harbin Institute of Technology, Harbin 150001, \\ China; hitjoining@hit.edu.cn (T.L.); hithepeng@hit.edu.cn (P.H.); 13b309019@hit.edu.cn (P.L.) \\ 2 Yik Shing Tat Industrial Co., Ltd., Shenzhen 518101, China; yangming.hitsz@gmail.com \\ 3 Department of Chemical and Biomolecular Engineering, KAIST, 291 Daehak-ro, Yuseong-gu, \\ Daejeon 305-338, Korea; 20104170@kaist.ac.kr (M.J.); moonchanhwang@kaist.ac.kr (W.-C.H.) \\ 4 Department of Nano-Structured Materials Research, National NanoFab Center (NNFC), 291 Daehak-ro, \\ Yuseong-gu, Daejeon 305-338, Korea \\ 5 Department of Materials Science and Engineering, KAIST, 291 Daehak-ro, Yuseong-gu, Daejeon 305-338, \\ Korea; kwpaik@kaist.ac.kr \\ * Correspondence: syzhang@hit.edu.cn or syzhang@kaist.ac.kr
}

Received: 11 December 2017; Accepted: 3 January 2018; Published: 9 January 2018

\begin{abstract}
Micron sizes solder metallurgical joints have been applied in a thin film application of anisotropic conductive film and benefited three general advantages, such as lower joint resistance, higher power handling capability, and reliability, when compared with pressure based contact of metal conductor balls. Recently, flex-on-board interconnection has become more and more popular for mobile electronic applications. However, crack formation of the solder joint crack was occurred at low temperature curable acrylic polymer resins after bonding processes. In this study, the mechanism of SnBi58 solder joint crack at low temperature curable acrylic adhesive was investigated. In addition, SnBi58 solder joint cracks can be significantly removed by increasing the storage modulus of adhesives instead of coefficient of thermal expansion. The first approach of reducing the amount of polymer rebound can be achieved by using an ultrasonic bonding method to maintain a bonding pressure on the SnBi58 solder joints cooling to room temperature. The second approach is to increase storage modulus of adhesives by adding silica filler into acrylic polymer resins to prevent the solder joint from cracking. Finally, excellent acrylic based SnBi58 solder joints reliability were obtained after 1000 cycles thermal cycling test.
\end{abstract}

Keywords: adhesive thermos-mechanical property; SnBi58 solder joint morphology; flex-on-board assembly; thermal compression bonding; ultrasonic bonding

\section{Introduction}

Amid the current trend for wearable electronics assembly, flex-on-board (FOB) assembly is attracting a greater attention because of its important role in replacing conventional physical contacts-based socket type interconnections. In the case of conventional socket type interconnections, there are three main drawbacks, which include: physical contact, large package size, and low packaging density [1]. For reducing the package thickness from $4 \mathrm{~mm}$ to $0.1 \mathrm{~mm}$, and fine pitch capability to less than $100 \mu \mathrm{m}$, FOB application, as shown in Figure 1, is an obvious choice in the replacement of conventional socket type interconnections [2]. 


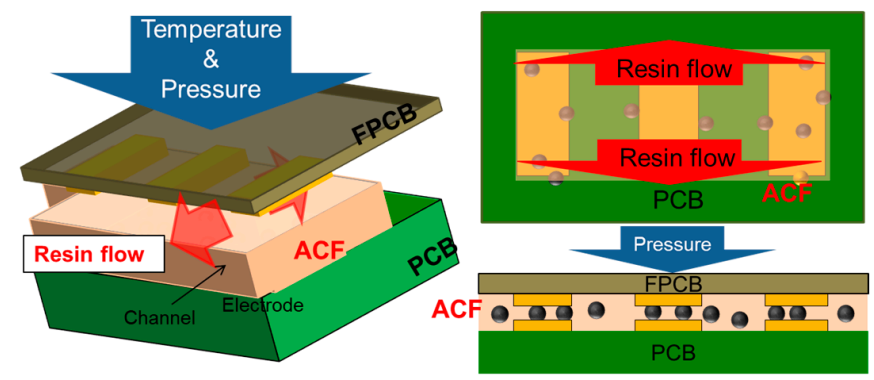

Figure 1. Bonding process and formed flex-on-board interconnection.

The anisotropic conductive films (ACFs) are the interconnection materials to assembly FOB applications. ACFs generally consist of thermosetting polymer resins and micron-sized conductive particles, with the cruel requirement in fine pitch applications of providing electrical paths only in the z-axis, and insulation property by polymer resins in the $x-y$ plane. Physical contacts between the conductive particles and metal electrodes are the main electrical paths for micron-sized Au/Ni coated polymer ball joints and metal ball joints, but they will easily fail with the thermal expansion of polymer resin in high-power applications [3]. Therefore, micron-sized solder particles are added to polymer resin matrixes to replace micron-sized $\mathrm{Au} / \mathrm{Ni}$ coated polymer ball joints and metal ball joints to form metallurgical joints for lower joint resistance, higher power-handling capability, and better reliability, in Figure 2.

\section{$\checkmark$ Comparison conventional $\mathrm{Ni}$ and Solder balls}

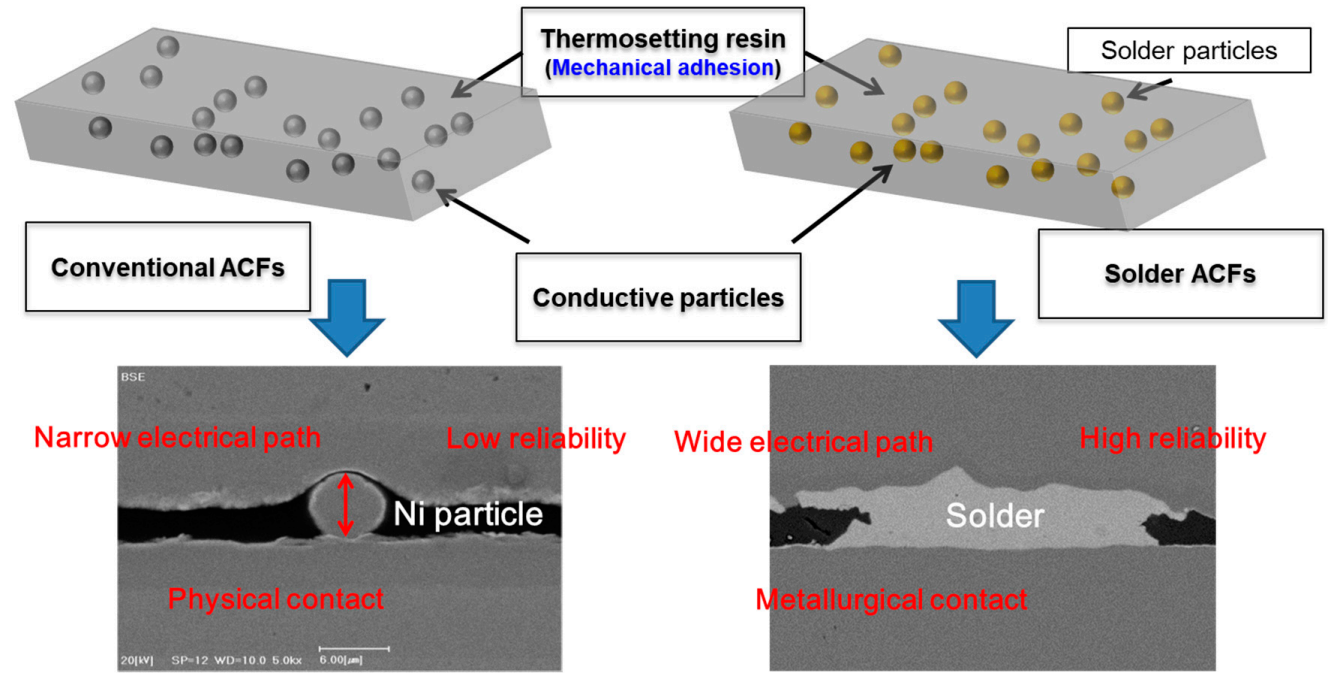

Figure 2. A comparison of the conventional $\mathrm{Ni}$ and $\mathrm{Sn}$ solder metallurgical anisotropic conductive films (ACFs) joints.

In these solder ACFs, solders are Sn-based Sn-58Bi or Sn-Ag-Cu (SAC) alloys, depending on their melting temperature. $\mathrm{Sn}-58 \mathrm{Bi}\left(139^{\circ} \mathrm{C}\right)$ and $\mathrm{Sn}-3.0 \mathrm{Ag}-0.5 \mathrm{Cu}\left(221^{\circ} \mathrm{C}\right)$ solder ACFs can be assembled at $200{ }^{\circ} \mathrm{C}$ and $250{ }^{\circ} \mathrm{C}$ bonding temperature, respectively. According to previous study [4], $200^{\circ} \mathrm{C}$ was the optimized bonding temperature for Sn-58Bi solder ACFs joints in FOB applications. Below $200{ }^{\circ} \mathrm{C}$, resin traps were always found at $\mathrm{Sn}-58 \mathrm{Bi}$ solder joints. Above $200^{\circ} \mathrm{C}$, a joint height larger than solder ball dimension was achieved and even open circuits were formed, due to ACFs faster curing property.

To remove the Sn solder oxide layer for enhanced performance, two bonding methods have been used. One method uses an ultrasonic (US) bonding [5], and the other method is to add flux materials in adhesives using a conventional thermo-compression (TC) bonding [6]. Figure 3 shows the difference 
on the final completed moment between the TC bonding and US bonding methods in Figure 3. At the end of the TC bonding, the bonding pressure will be automatically lifted-up, however, the lift-up time of the bonding pressure can be controlled in the cooling process by the US bonding.
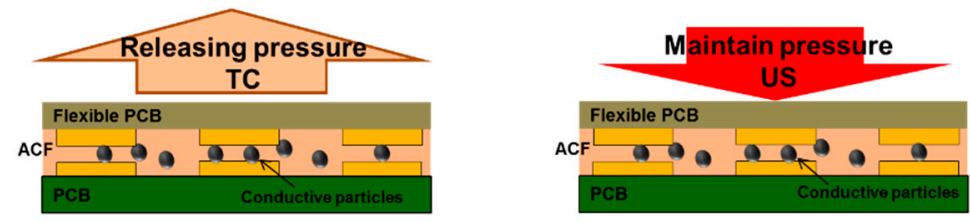

Figure 3. The comparison of the completed moment between thermo-compression (TC) and ultrasonic (US) bonding: Releasing pressure and maintaining pressure.

Because the polymer resins were still at a high temperature environment when the bonding pressure was removed, the potential polymer rebound without the bonding pressure protect might be issued for solder ACFs joints, due to viscoelastic property. The solder joint was molten and could not provide any protect against the polymer rebound, as a result, cracks of solder ACFs joints would occur. In terms of viscoelastic theory, the polymer resin shows a dominant elastic property instead of the viscos property, because the polymer rebound and the disappear of the bonding pressure were in a vertical direction and the polymer rebound was theoretically caused by the shape recover of polymer resins without pressure protect at a high temperature. In addition, there was not any change of the horizontal sheer forces in the polymer resin on the moment of releasing bonding pressures [7]. Therefore, the elastic property of polymer resins at a high temperature was very important for cracking solder ACFs joints. However, there is no research regarding this area, and no available method to solve the solder joint cracks. Figure 4 shows a Sn-58Bi solder joint crack after a FOB assembly.

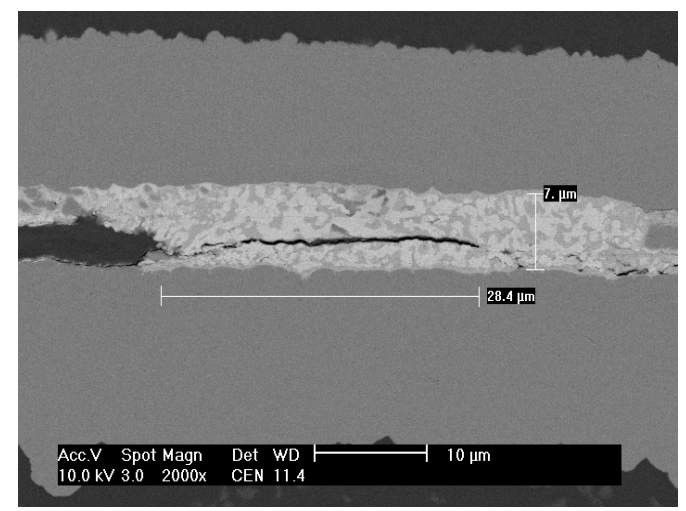

Figure 4. SnBi58 solder joint cracks after a thermo-compression bonding.

In this study, we used adhesives thermos-mechanical property to illustrate resin elastic property when the bonding pressures were removed, and the corresponding SnBi58 solder joint morphologies were observed using various adhesives materials and two bonding methods. In details, three typical adhesive resins were compared with different thermos-mechanical properties. It was found that solder joint cracks were always made at fast curable acrylic resins with a poor thermos-mechanical property. Its glass transition temperature $(\mathrm{Tg})$ was too low at $45^{\circ} \mathrm{C}$. To solve the solder joint cracks at this $45^{\circ} \mathrm{C}$ low Tg material, we developed the lift-up time of bonding pressure in the cooling process by an US bonding method. Using this, crack-free solder ACF joints were achieved when bonding pressure was lift-up in the cooling process until $70 \mathrm{~s}$ lower than polymer Tg. The second method to add $0.2 \mu \mathrm{m}$ silica fillers to increase resin modulus using a conventional TC bonding. It was found that cracks at $\mathrm{Sn}-58 \mathrm{Bi}$ joints can be removed by adding to $10 \mathrm{wt} \%$ amount of $\mathrm{SiO}_{2}$, where $1.38 \mathrm{MPa}$ storage modulus was needed at $200{ }^{\circ} \mathrm{C}$. Finally, $-45 / 125^{\circ} \mathrm{C}$ reliability was carried out to evaluate the improved solder 
ACFs joints for low temperature curable acrylic resins by 1000 cycles. All of the joint crack experiments are conducted and lead by our research group.

\section{Experiments}

\subsection{Test Vehicles and Materials}

1-mm-thick FR-4 printed circuit board (PCB) and a 50- $\mu$ m-thick polyimide based flexible printed circuit (FPCB) substrate which plotted $500-\mu \mathrm{m}$-pitch Cu patterns with electroless nickel immersion gold (ENIG) finish in Figure 5.

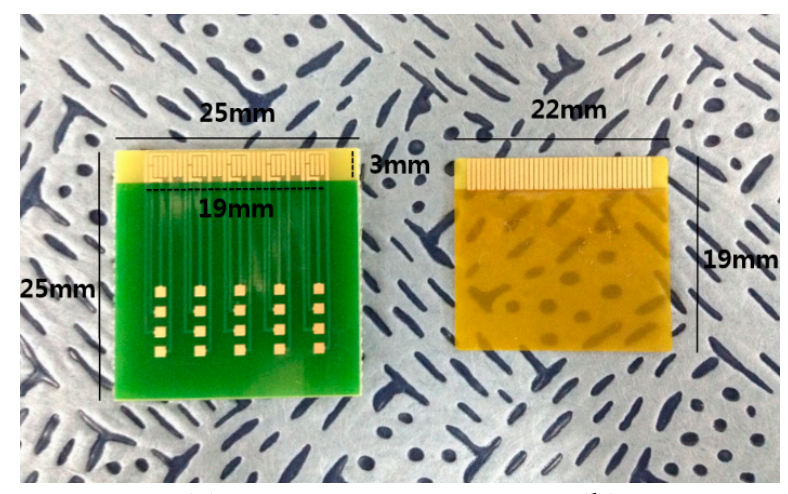

(a)

(b)

Figure 5. 500- $\mu$ m-pitch flex-on-board (FOB) test vehicles. (a) printed circuit board (PCB), (b) polyimide based flexible printed circuit (FPCB).

For the ACFs, three kinds of thermosetting polymer resins were used, in name of acrylic base, imidazole base and cationic epoxy base. These products were bought from a commercial adhesive company. We added $5 \mathrm{wt} \%$ 8- $\mu \mathrm{m}$-diameter Ni particles, $0.2 \mu \mathrm{m}$ silica fillers, $30 \mathrm{wt} \% 25-32 \mu \mathrm{m}$ diameters Sn58Bi particles, and $2 \mathrm{wt} \%$ flux material into the pure bought adhesives and then proceeded the film coating process. So, we got the anisotropic conductive films.

$\mathrm{Ni}$ particles were used to resist bonding pressures and maintain solder joint morphology during bonding in Figure 6. Silica fillers were directly added and mixed with the solution of polymer resins and conductive particles. Table 1 gives the specifications of the added materials, such as weight percentages of the pure polymer resins and the calculated volume percentages of the total ACFs materials with additives. Figure 7 shows the fresh ACFs were put on the PCB ENIG metal electrodes before bonding process [8].

Table 1. The specification of solder ACFs.

\begin{tabular}{|c|c|c|c|c|c|c|c|c|}
\hline \multirow{2}{*}{$\begin{array}{l}\text { Solder } \\
\text { ACFs }\end{array}$} & \multicolumn{4}{|c|}{ Weight Percentage } & \multicolumn{4}{|c|}{ Calculated Volume Percentage } \\
\hline & $\begin{array}{l}\text { SnBi58 Solder } \\
\left(8.56 \mathrm{~g} / \mathrm{cm}^{3}\right)\end{array}$ & $\begin{array}{c}\text { Polymer Resin } \\
\left(1.25 \mathrm{~g} / \mathrm{cm}^{3}\right)\end{array}$ & $\begin{array}{l}\text { Ni Particle } \\
\left(8.9 \mathrm{~g} / \mathrm{cm}^{3}\right)\end{array}$ & $\begin{array}{l}\text { Silica Filler } \\
\left(2.65 \mathrm{~g} / \mathrm{cm}^{3}\right)\end{array}$ & $\begin{array}{c}\text { SnBi58 Solder } \\
\left(8.56 \mathrm{~g} / \mathrm{cm}^{3}\right)\end{array}$ & $\begin{array}{c}\text { Polymer Resin } \\
\left(1.25 \mathrm{~g} / \mathrm{cm}^{3}\right)\end{array}$ & $\begin{array}{l}\text { Ni Particles } \\
\left(8.9 \mathrm{~g} / \mathrm{cm}^{3}\right)\end{array}$ & $\begin{array}{l}\text { Silica Filler } \\
\left(2.65 \mathrm{~g} / \mathrm{cm}^{3}\right)\end{array}$ \\
\hline ACF 1 & $30 \%$ & 1 & $5 \%$ & $0 \%$ & $6.25 \%$ & $92.75 \%$ & $1 \%$ & $0 \%$ \\
\hline ACF 2 & $30 \%$ & 1 & $5 \%$ & $5 \%$ & $6.1 \%$ & $89.7 \%$ & $0.97 \%$ & $3.23 \%$ \\
\hline ACF 3 & $30 \%$ & 1 & $5 \%$ & $10 \%$ & $5.9 \%$ & $86.9 \%$ & $0.93 \%$ & $6.27 \%$ \\
\hline
\end{tabular}

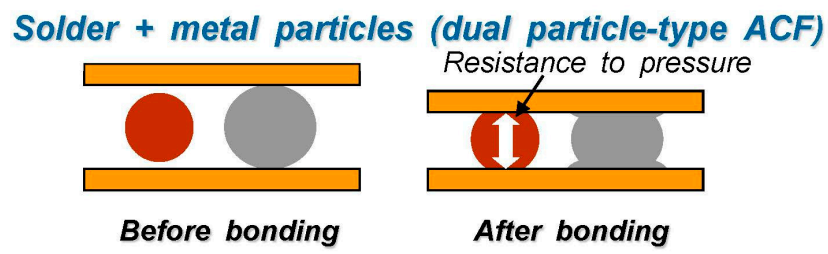

Figure 6. Role of Ni spacer at solder ACFs joints. 


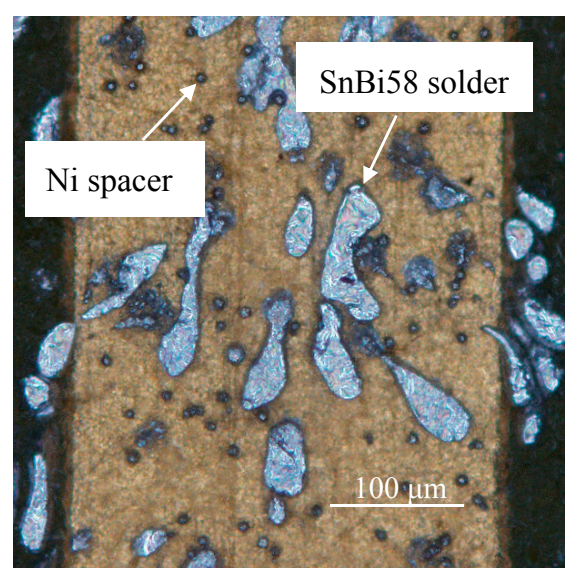

Figure 7. The laminated ACFs on the PCB electroless nickel immersion gold (ENIG) metal electrodes.

\subsection{Two Bonding Methods}

\subsubsection{Thermo-Compression Bonding}

The bonding parameters (peak temperature, time, and pressure) were set as $200^{\circ} \mathrm{C} 10 \mathrm{~s}$ and $1 \mathrm{MPa}$. Figure 8 shows a schematic of TC bonding process. Polymer resin was cured by the heat conduction from the high temperature of hot bar. Figure 9 gives the in-situ temperature of solder ACFs joint by a TC bonding, which is measured by a K-type thermocouple every $0.1 \mathrm{~s}$. In this case, the hot-bar was automatically lift-up on the peak temperature.

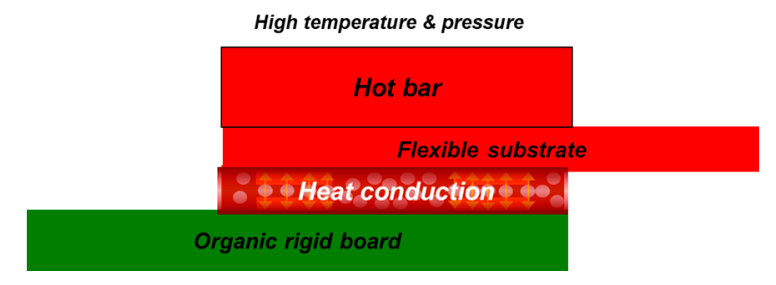

Figure 8. A schematic of TC bonding.

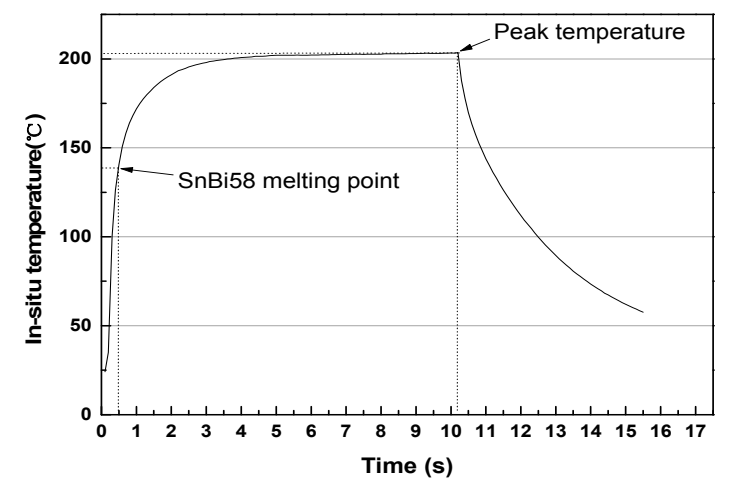

Figure 9. The in-situ temperature profile of solder ACFs joint by a TC bonding.

\subsubsection{Ultrasonic Bonding}

Figure 10 shows the schematic of ultrasonic bonding process. In this case, ultrasonic vibration was applied at room temperature and polymer resin was cured by the spontaneous ultrasonic vibration. Bonding pressure can be controlled as a function of time. So, Figure 11 gives the in-situ ACFs joint temperature profile and the delaying ultrasonic horn lift-up time using the ultrasonic bonding. In this 
case, ultrasonic vibration is applied for $10 \mathrm{~s}$, and then the $1 \mathrm{MPa}$ bonding pressure was maintained until $70 \mathrm{~s}$ to room temperature.

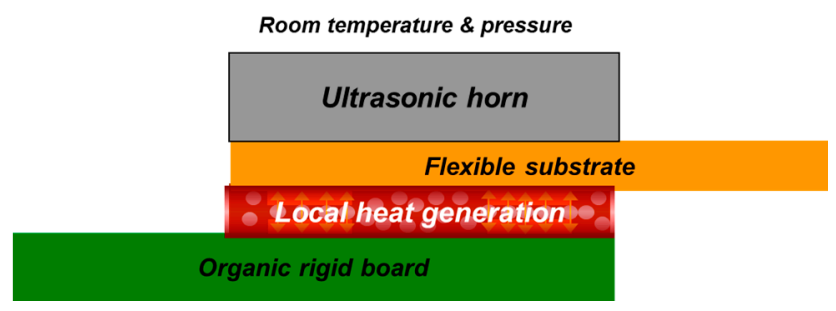

Figure 10. A schematic of ultrasonic bonding.

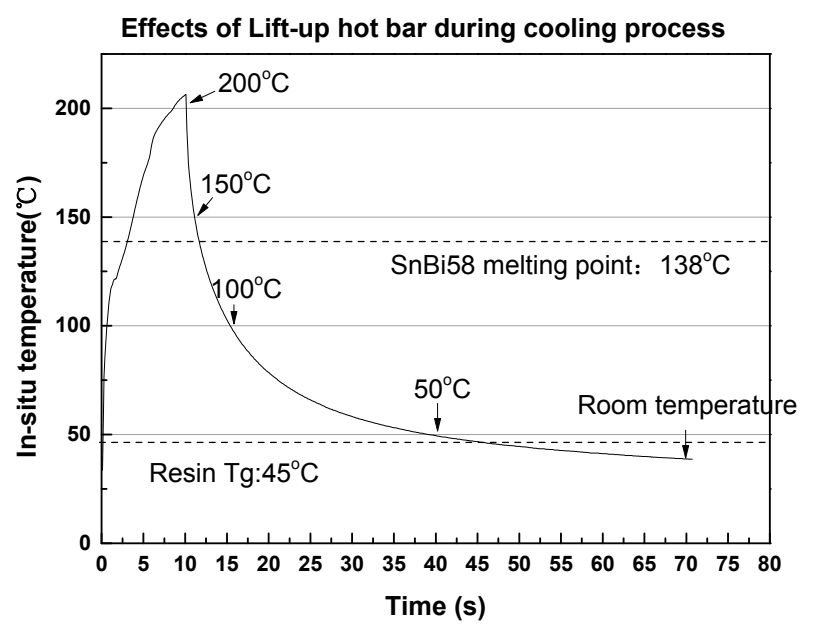

Figure 11. The in-situ temperature profile of solder ACFs joint by US bonding.

\subsection{Differential Scanning Calorimetry (DSC)}

For analysis of solder ACFs joint crack, DSC was performed. The heating rate was $20{ }^{\circ} \mathrm{C} / \mathrm{min}$ from $30^{\circ} \mathrm{C}$ to $300{ }^{\circ} \mathrm{C}$ and furnace cooled to room temperature at a nitrogen environment. Although a rate of $10^{\circ} \mathrm{C} / \mathrm{min}$ is traditional, a faster heating rate for the metallic solder materials does not affect much regarding solder melting temperatures. Polymer resin was not tested in this experiment, so the glass transition temperature of resin was not considered. At here, solder melting and solidifying behaviors can be adjusted. The test sample was $20 \mathrm{mg}$ weight.

\subsection{Thermomechanical Analysis}

A thermomechanical analyzer (DMA) was used to measure the viscoelastic property of the cured polymer resin as a function of temperature. Figure 12 shows the DMA measurement for cured ACFs. A 10-mm-length, 2.5-mm-width, and 50- $\mu \mathrm{m}$-thickness resin film was under a tensile force, where the static stress was $50 \mathrm{mN}$ and the dynamic stress was $10 \mathrm{mN}$ under $0.1 \mathrm{~Hz}$ sinusoidal load, and the temperature profile was fixed at a heating rate of $5{ }^{\circ} \mathrm{C} / \mathrm{min}$ from $30{ }^{\circ} \mathrm{C}$ to $200{ }^{\circ} \mathrm{C}$. For the elastic property in the $\mathrm{z}$ direction, the elastic strain was discussed. According to Equation (1), elastic strain is the elastic deformation of polymer resin driven by the sinusoidal tensile load, which is the ratio of length change $(\Delta L)$ over the initial ACF length $(L)$. The higher elastic strain indicates larger plastic rebound of polymer resin. In addition, the coefficient of thermal expansion (CTE) of adhesives were also measured by a $50 \mathrm{mN}$ constant tensile force as temperature increased.

$$
\text { Strain }=\frac{\Delta L}{L}
$$




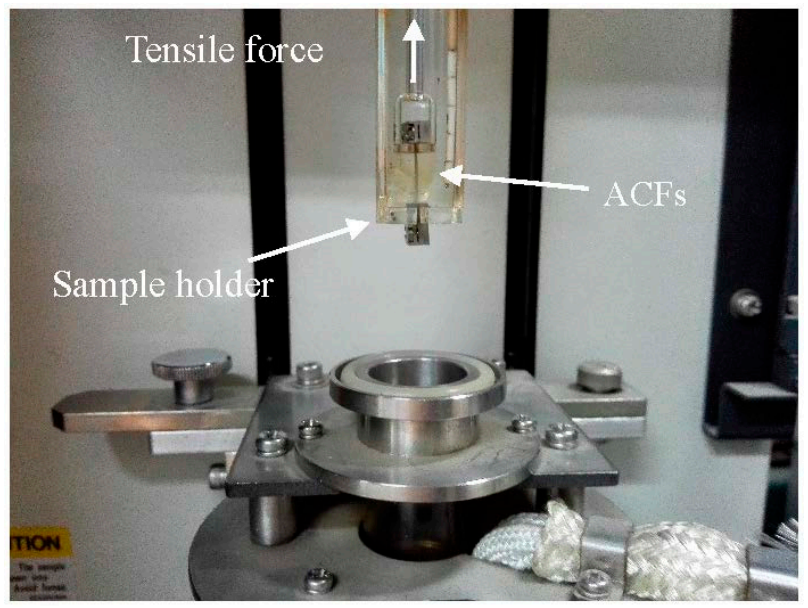

Figure 12. DMA thermo-mechanical property measurement for cured ACFs [9].

\subsection{Joint Resistance and Morphologies}

After bonding process, ACFs joint resistance was measured using a kelvin 4-point-probe method. From Ohm's Law, we know that resistance is equal to voltage divided by current. The resistance of the desired part can be known if we apply the constant current going through it and measure the voltage dropped across it. The calculated ratio of overlapped voltage to current is regarded as the joint resistance [10].

In our design, delta mode measurement by KI 6220 nano-voltmeter from a Keithley company at America was used. The constant current was applied through both PCB and FPCB Cu lines and solder $\mathrm{ACF}$ joints, and the voltage measurement was from another way and the overlapped grown part was the measured solder ACFs areas in Figure 13. 10 times were set up for the accurate measurement of one solder ACF joint area. Area size was $0.3 \mathrm{~mm}^{2}$. 40 channels were measured for one kind of ACF joint.

In addition, solder ACFs joint images after the bonding process were observed by a scanning electron microscope (SEM). The backscattered electron mode and 2000 magnification were selected for an obvious comparison between Sn and Bi elements. Typical solder information, such as solder joint heights, shapes, morphologies, and cracks, was recorded.

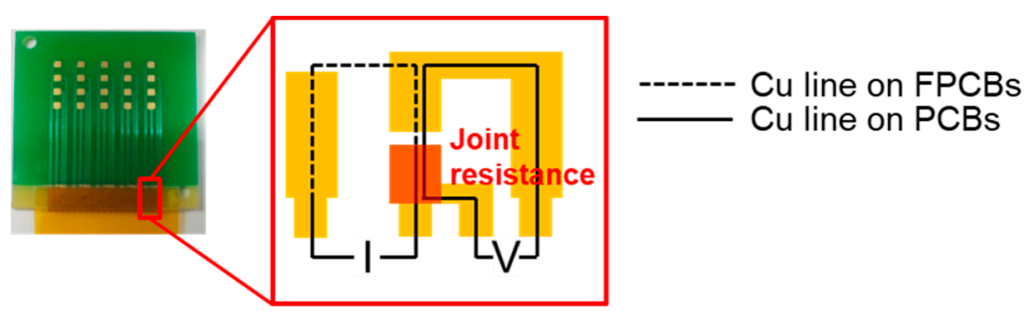

Figure 13. Electrical design for a four-point-probe measurement.

\subsection{Reliability Evaluation}

A $-45 / 125{ }^{\circ} \mathrm{C}$ reliability was carried out to evaluate the improved solder ACFs joints at low $\mathrm{Tg}$ materials for 1000 cycles. The test samples for the reliability test were TC bonded using acrylic based solder ACFs with 0,5 , and $10 \mathrm{wt} \%$ of $0.2 \mu \mathrm{m}$ silica fillers added. The reliability test was performed with a dwell time of $15 \mathrm{~min}$ from $-40{ }^{\circ} \mathrm{C}$ to $125^{\circ} \mathrm{C}$ for 1000 cycles. Joint contact resistances were measured every 200 cycles. After 1000 cycles, failure modes of ACF joints were detected by SEM analysis. 


\section{Results and Discussion}

\subsection{Elastic Property of Polymer Resin}

Figure 14 shows a $50 \mathrm{mN}$ tensile sinusoidal load with $10 \mathrm{mN}$ amplitude and $0.1 \mathrm{~Hz}$ frequency in DMA. Figure 15 illustrates the measured strain of acrylic based SnBi58 solder ACFs in respect to the sinusoidal load in DMA as a function of temperature. Viscoelastic materials, such as elastomers, amorphous polymers, and semicrystalline polymers [11], were always in the polymer resins. For example, elastomers are usually thermosets as well as it may also be thermoplastic. The long polymer chains are cross-linked during a curing reaction. The molecular structure of elastomers can be imagined as Figure 16 and the dots represent cross-links. When the stress is removed, B configuration will return to the original A configuration [12]. This elasticity is derived from the long chains to reconfigure themselves to distribute an applied stress. This is the reason for the elastic behaviors of elastomers.

In Figure 15, it was found that the measured strain was increased at high temperature, especially above Tg. Actually, the measured strain is divided into two parts, the first is polymer relaxation under a tensile force and the second is elastic strain respond to sinusoidal mechanical load. Both the polymer relaxation and elastic strain were increased as the temperature increased. This is because elastomers that have cooled to a glassy or crystalline phase will have less mobile chains, and, consequentially, less elasticity than those manipulated higher than the glass transition temperature of the polymer [13]. So the polymer $\mathrm{Tg}$ is very important to reduce elasticity.

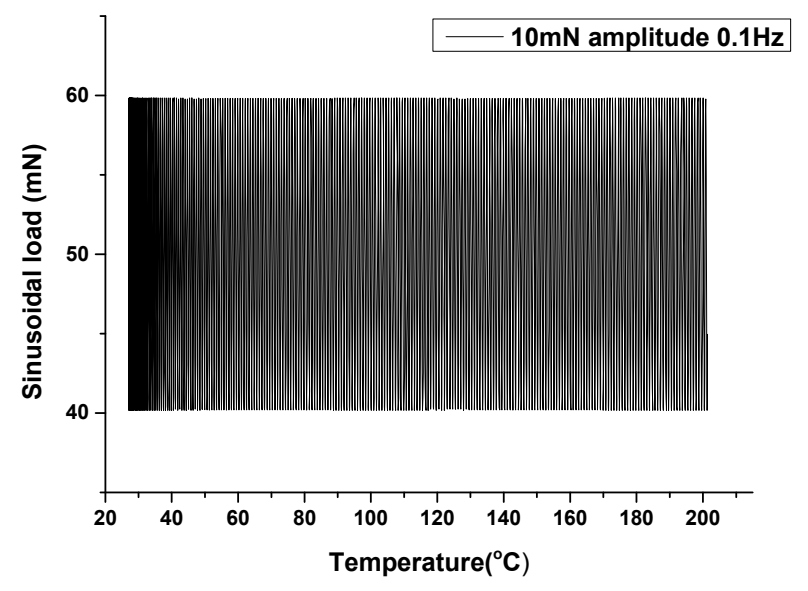

Figure 14. Mechanical load in a tensile mode by DMA.

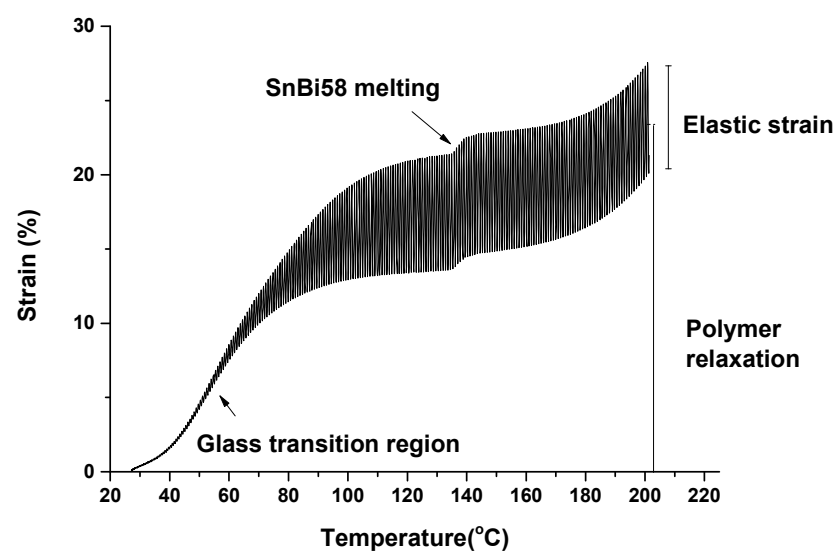

Figure 15. Strain of acrylic based SnBi58 solder ACFs in respect to a sinusoidal load in DMA as a function of temperature. 


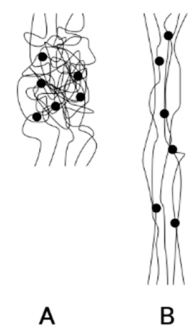

Figure 16. Elastomer structures: $(\mathbf{A})$ is an unstressed polymer; $(\mathbf{B})$ is the same polymer under stress.

Because $\mathrm{Tg}$ of acrylic resin is $45^{\circ} \mathrm{C}$, polymer transits from a rigid glass state to a soft rubber state, elastic strain in respect to same driving sinusoidal force is small below $\mathrm{Tg}$ and becomes large above $\mathrm{Tg}$ due to viscoelastic property. What is more, SnBi58 solder particles are made up of $30 \mathrm{wt} \%$ of total solder ACFs, and the strain measurement is in a tensile mode, so the dimension was stretched when the solder melts on $139^{\circ} \mathrm{C}$.

In this study, viscoelastic property was studied using a dynamic mechanical analysis method, which is by applying a small oscillatory stress and measuring the resulting strain. Complex dynamic modulus $G$ can be used to represent the relations (2) to (4) between the oscillating stress and strain [14]:

$$
G=G^{\prime}+\mathrm{i} G^{\prime \prime}
$$

where $i^{2}=-1, G^{\prime}$ is the storage modulus and $G^{\prime \prime}$ is the loss modulus:

$$
\begin{aligned}
G^{\prime} & =\frac{\sigma_{0}}{\varepsilon_{0}} \cos \delta \\
G^{\prime \prime} & =\frac{\sigma_{0}}{\varepsilon_{0}} \sin \delta
\end{aligned}
$$

where $\sigma_{0}$ and $\varepsilon_{0}$ are the amplitudes of the applied stress and the measured elastic strain, respectively, and $\delta$ is the phase shift between them. Because $G^{\prime}$ and $G^{\prime \prime}$ only have phase shift difference, and both of them can represent $\varepsilon_{0}$. So, we use $G^{\prime}$ storage modulus to estimate resin elastic property. Figure 17 is the derived storage modulus of acrylic based polymer resin from DMA. Since acrylic resin is a low $\mathrm{Tg}$ material, the lower storage modulus indicates the larger elasticity of polymer resin.

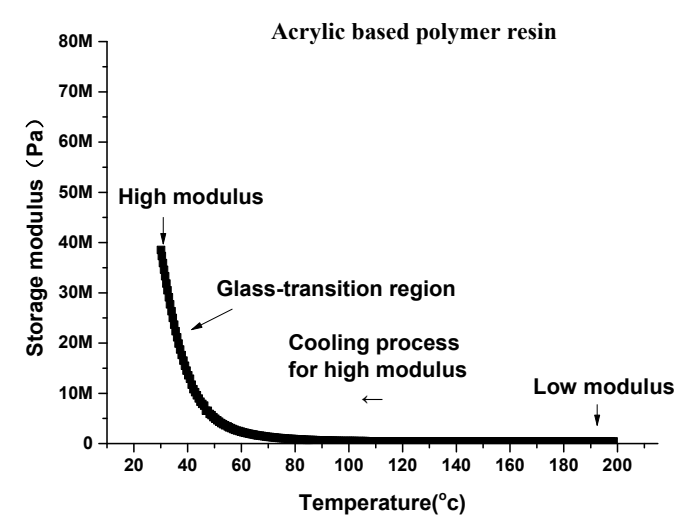

Figure 17. Storage modulus of acrylic based solder ACF as a function of temperature.

\subsection{Effects of Resin Tg on Solder Joint Morphology}

We prepared three types polymer resins with different $\mathrm{Tg}$ in Figure 18. When compared with acrylic adhesives by $45^{\circ} \mathrm{C} \mathrm{Tg}$, the conventional epoxies cured by imidazole and cationic agent showed higher $\operatorname{Tg}$ (over $100^{\circ} \mathrm{C}$ ) and storage modulus. Especially at $200^{\circ} \mathrm{C}$ when hot-bar was removed at the 
end of TC bonding, the cured acrylic adhesives only had 0.4 MPa storage modulus, but cationic epoxy and imidazole epoxy showed 7.1 MPa and $5.7 \mathrm{MPa}$, respectively.

Figure 19 shows SnBi58 solder ACFs joints morphologies using three types resins and a conventional TC bonding method. It only showed cracks at acrylic adhesives, regardless of bonding pressures. However, there is no solder joint cracks when using other two types adhesive materials under same bonding pressures. Therefore, our first conclusion is that solder joint crack can be solved by using higher $\mathrm{Tg}$ adhesives. In Figure 19, cracks are found mostly along the outer interface and sporadically inside the solder, probably due to the weak intermetallic compound of $\mathrm{Ni}_{3} \mathrm{Sn}_{4}$ formation at the interface after bonding. However, in Figure 19g, cracks are found in the solder, probably due to the crack initiation at the weak point of solder joints and then propagation into the bulk solder joints. All of the results can be replicate for the same specimens of ACFs recipes.

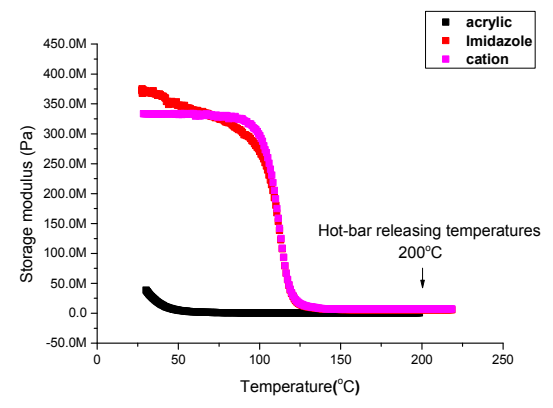

(a)

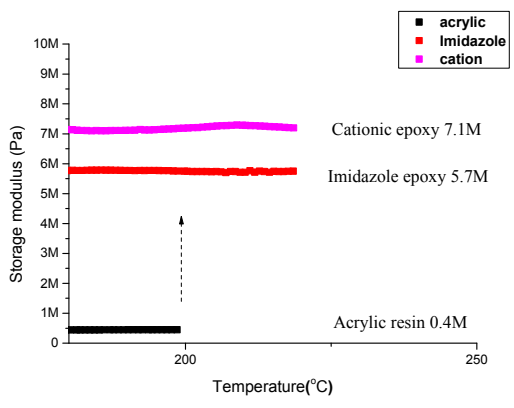

(b)

Figure 18. Thermal mechanical properties of typical adhesives films. (a) $30^{\circ} \mathrm{C}-250{ }^{\circ} \mathrm{C}$ (b) magnified $200{ }^{\circ} \mathrm{C}-250{ }^{\circ} \mathrm{C}$.
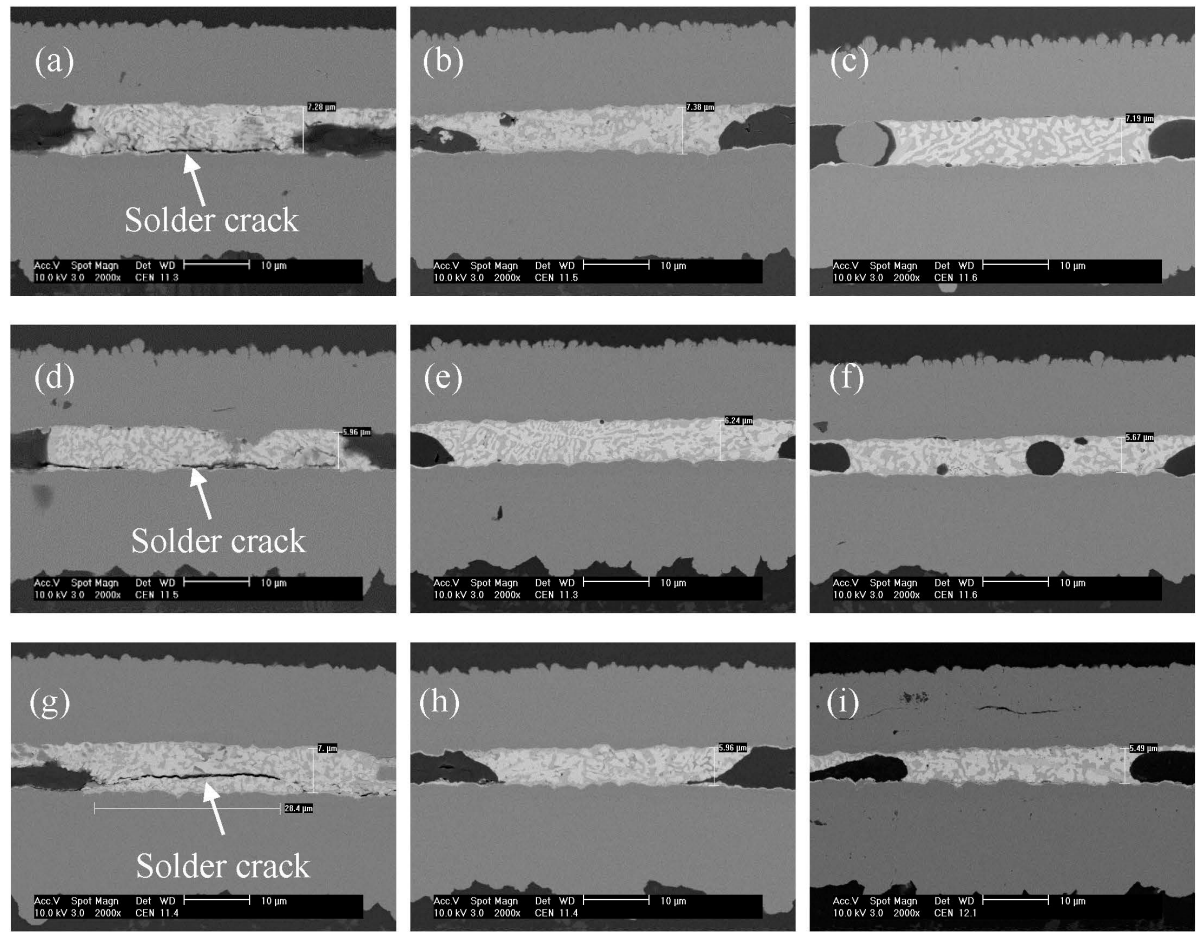

Figure 19. SEM images of SnBi58 solder ACFs joints by $200{ }^{\circ} \mathrm{C} 10 \mathrm{~s}$ TC bonding as a function of resin types and bonding pressures. (a,d,g) Acrylic base resins with 1, 2, and $3 \mathrm{MPa}$ bonding pressures; (b,e,h) Imidazole epoxy with 1, 2, and $3 \mathrm{MPa}$ bonding pressures; (c,f,i) Cationic epoxy with 1, 2, and $3 \mathrm{MPa}$ bonding pressures. 
Although we assumed that the molten solder joints were cracked under tensile forces by the polymer rebound when bonding pressures were removed at high temperature, however, there is another concern by CTE mismatch between shrink adhesives and solders during the cooling process. Therefore, we carried out the cooling analysis.

Figure 20 shows endothermic and exothermic behaviors of SnBi58 solder materials in a DSC analysis. In a heating period, SnBi58 solder melts at $139{ }^{\circ} \mathrm{C}$ and stays at a liquid state until cooling to $125^{\circ} \mathrm{C}$, and SnBi58 solders were totally solid below $90^{\circ} \mathrm{C}$. It means that the cooled adhesives are able to cause the solidified SnBi58 solder joints cracks above $90{ }^{\circ} \mathrm{C}$, because the fully solid SnBi58 joint is with 30.9 Gpa young's modulus, which is a hard material. Figure 21 summarizes thermal expansion properties of three typical adhesives. Table 2 gives shrinkage percentages of typical adhesives films during cooling. $90{ }^{\circ} \mathrm{C}$ is lower than $\mathrm{Tg}$ of imidazole epoxy and cation epoxy, so there was a huge dimension shrinkage when cooling through glass transition region at 2 epoxies. From $200{ }^{\circ} \mathrm{C}$ cooling to $90{ }^{\circ} \mathrm{C}$, acrylic resin, imidazole epoxy, and cation epoxy showed $-11.2 \%,-13.2 \%$, and $-5.2 \%$ dimension shrinkage, however, there is no solder joint cracks at imidazole epoxy based SnBi58 solder ACFs joints in Figure 19. Thus, solder ACFs joint cracks were not related with higher compressive stress by adhesives shrinkages in the cooling process. The mechanism of solder ACFs joint cracks should be adhesive rebound, especially for lower modulus acrylic adhesives.

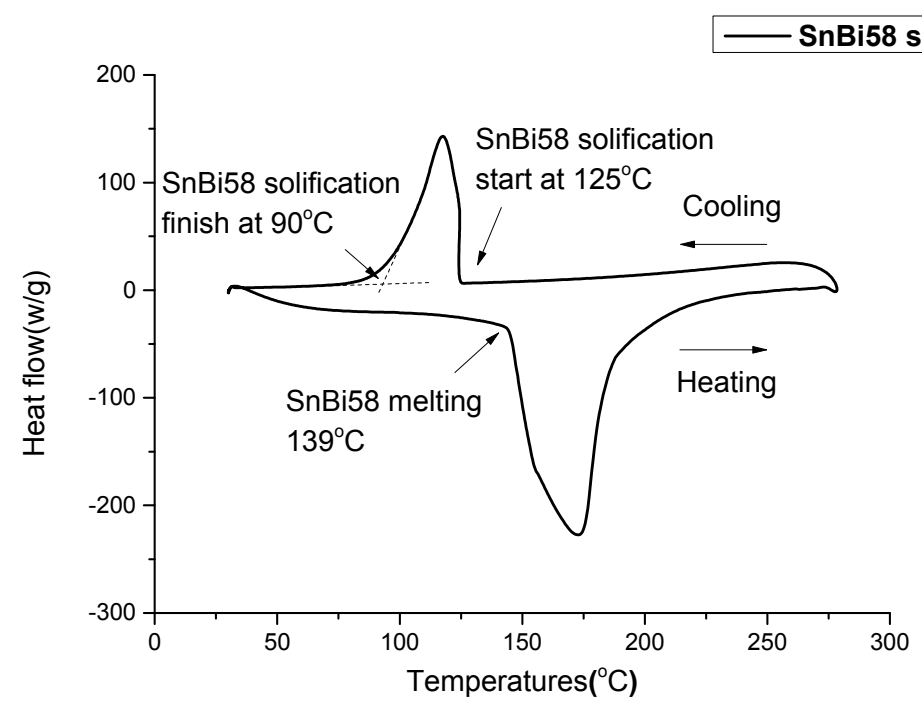

Figure 20. DSC behaviors of SnBi58 solder during heating and cooling process.

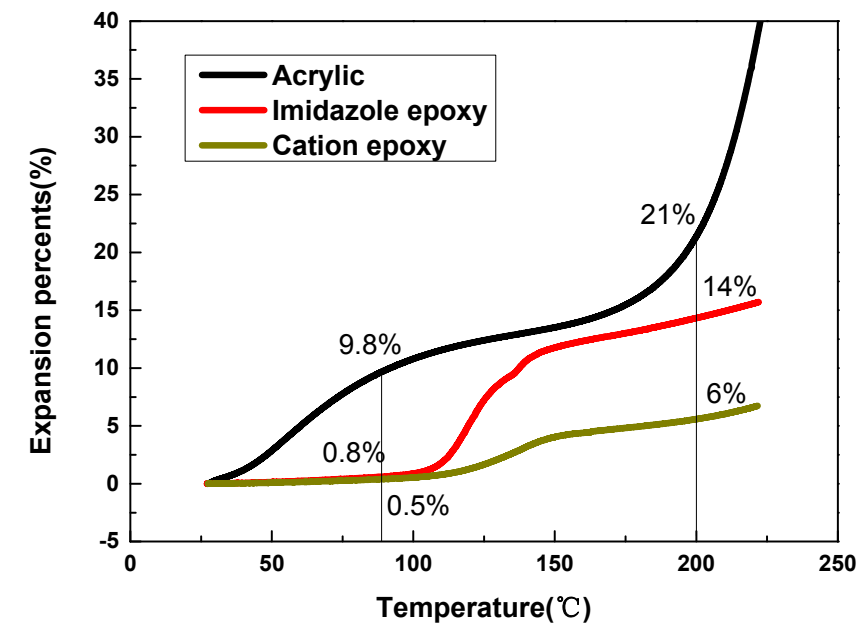

Figure 21. Thermal expansion properties of typical adhesives films. 
Table 2. Shrinkage percentages of typical adhesives films during cooling.

\begin{tabular}{cccc}
\hline Dimension Change & Acrylic & Imidazole Epoxy & Cation Epoxy \\
\hline $200{ }^{\circ} \mathrm{C}$ & $21 \%$ & $14 \%$ & $6 \%$ \\
$90^{\circ} \mathrm{C}$ & $9.8 \%$ & $0.8 \%$ & 0.8 \\
200 cooling to $90{ }^{\circ} \mathrm{C}$ & $-11.2 \%$ & $-13.2 \%$ & $-5.2 \%$ \\
\hline
\end{tabular}

\subsection{Effects of Ultrasonic Bonding on Increasing Resin Modulus}

Learning from that high modulus may help to solve the solder joint morphology; an ultrasonic bonding with maintaining pressures in the cooling process was tried. Table 3 summarized increased storage modulus of acrylic adhesives at lower temperature. Figure 22 shows the acrylic based SnBi58 solder ACFs joint morphologies during an US bonding method with different lift-up time of bonding tool. It was found that a crack-free SnBi58 solder ACFs joint can be obtained by maintaining pressure below $30^{\circ} \mathrm{C}$, due to higher storage modulus of the acrylic adhesives below its $\operatorname{Tg}\left(45^{\circ} \mathrm{C}\right)$. At here, above $5 \mathrm{MPa}$ storage modulus was needed to avoid solder joint cracks using an ultrasonic bonding. The enhanced process was done by $70 \mathrm{~s}$, however, maintaining pressure time is too long for assembly over $30 \mathrm{~s}$.

Table 3. Storage modulus of acrylic adhesive during cooling process.

\begin{tabular}{cccccc}
\hline Temperature & $\mathbf{2 0 0}{ }^{\circ} \mathbf{C}$ & $\mathbf{1 5 0}{ }^{\circ} \mathbf{C}$ & $\mathbf{1 0 0}{ }^{\circ} \mathbf{C}$ & $50^{\circ} \mathbf{C}$ & $30^{\circ} \mathbf{C}$ \\
\hline Modulus & $0.4 \mathrm{MPa}$ & $0.44 \mathrm{MPa}$ & $0.53 \mathrm{MPa}$ & $5.2 \mathrm{MPa}$ & $34 \mathrm{MPa}$ \\
\hline
\end{tabular}
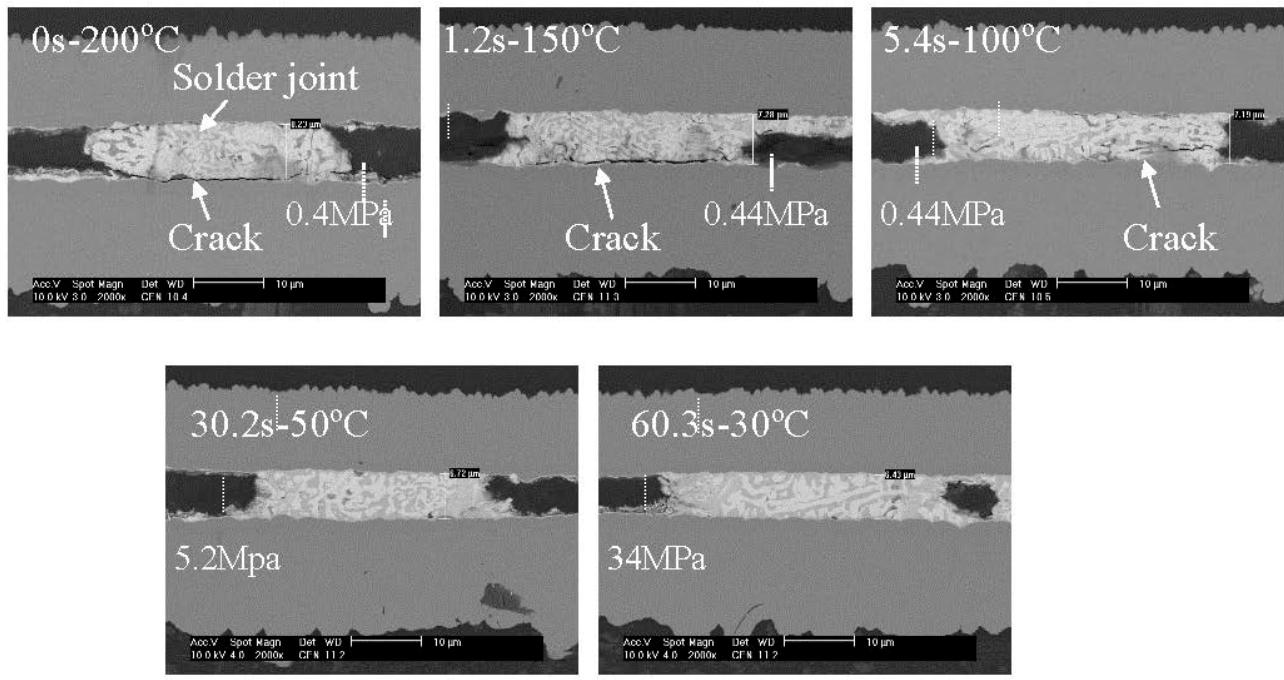

Figure 22. Effects of delaying ultrasonic horn lift-up times (0, 1.2, 5.4, 30.2, and $60.3 \mathrm{~s})$ on the SnBi58 solder ACFs joint morphologies.

\subsection{Effects of Silica Fillers on Increasing Modulus of Acrylic Resin}

From the ultrasonic bonding experiment, we concluded that resin modulus is the key to determine solder joint cracks. In order to find out the specific modulus for TC bonding to prevent solder joint from cracking, the second approach is to increase resin storage modulus by directly adding silica fillers into acrylic polymer resins. Figure 23 shows that the measured strain was decreased of acrylic based SnBi58 solder ACFs by adding 0,5 , and $10 \mathrm{wt} \%$ of $0.2 \mu \mathrm{m}$ silica fillers. Both the amount of the polymer expansion and the elastic strain of polymer resin were reduced by adding higher contents of silica fillers. 
Storage modulus of acrylic based SnBi58 solder ACFs with addition of 0, 5, and $10 \mathrm{wt} \% 0.2 \mu \mathrm{m}$ silica was shown in Figure 24. By adding 5 and $10 \mathrm{wt} \% 0.2 \mu \mathrm{m}$ silica filler, the storage modulus $0.4 \mathrm{MPa}, 0.9 \mathrm{MPa}$, and $1.3 \mathrm{MPa}$ was prepared at $200^{\circ} \mathrm{C}$, respectively.

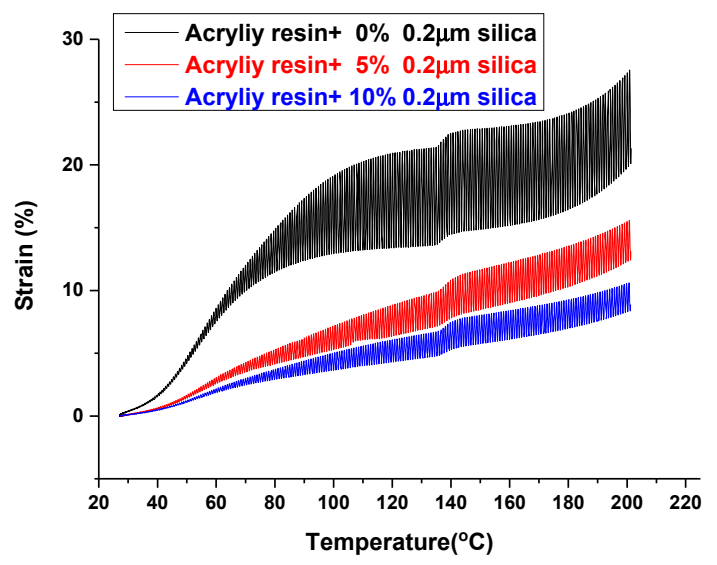

Figure 23. Strain of acrylic based SnBi58 solder ACFs with added silica fillers as a function of temperature.

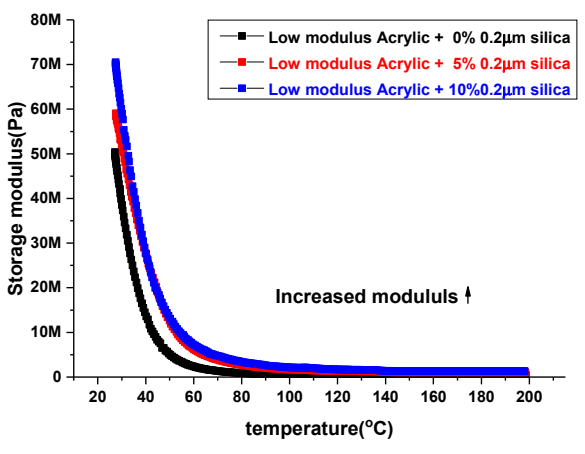

(a)

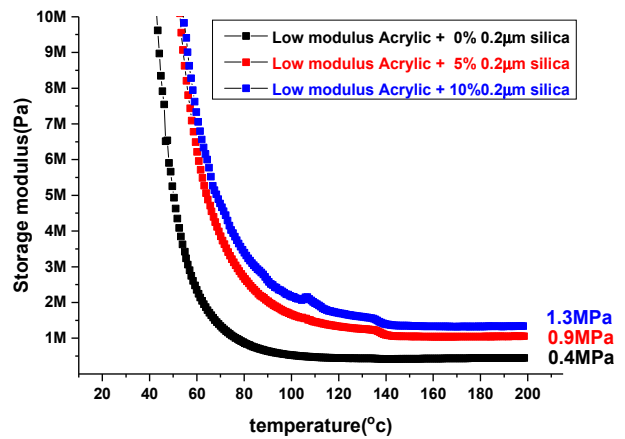

(b)

Figure 24. Elastic modulus of acrylic based SnBi58 solder ACFs by adding 0, 5, and $10 \mathrm{wt} \% 0.2 \mu \mathrm{m}$ silica fillers at (a) 0-80 MPa and (b) 0-10 MPa ranges.

\subsection{Reliability Evaluation for Modified Solder ACFs Joint}

Solder joint morphologies of acrylic based SnBi58 solder ACFs added by 0, 5, and $10 \mathrm{wt} \% 0.2 \mu \mathrm{m}$ silica filler before and after 1000 cycles reliability were listed in the Figure 25. According to the increment of elastic modulus by adding silica fillers from $0 \mathrm{wt} \%$ to $10 \mathrm{wt} \%$, as shown in Figure 24b, solder joint crack was completely removed at acrylic based SnBi58 solder ACF joints during $200{ }^{\circ} \mathrm{C}$ TC bonding with a pressure release during a cooling process. The optimized storage modulus for adhesives in TC bonding was above $1.38 \mathrm{MPa}$ at $200^{\circ} \mathrm{C}$ for crack-free SnBi58 solder joints.

In terms of reliability evaluation, Figure 25 shows the joint morphology after reliability. For acrylic based SnBi58 solder ACFs without added silica fillers, the joint failure occurred at the interface between SnBi58 solder joints and $\mathrm{Cu}$ metal electrode after 1000 cycles reliability test, because initial solder joint cracks have already existed before the reliability test. If $0.2 \mu \mathrm{m}$ silica filler was less than $5 \mathrm{wt} \%$, then a small solder crack still remained and propagated at SnBi58 solder joints, resulting in unstable joint contact resistance during reliability. If $0.2 \mu \mathrm{m}$ silica filler was more than $10 \mathrm{wt} \%$, a complete solder joint morphology was obtained after the 1000 cycles reliability, because initial solder joint crack was perfectly removed. Figure 26 shows electrical performance in the 1000 cycles T/C reliability [15], and the most stable joint resistance was achieved by adding $10 \mathrm{wt} \% 0.2 \mu \mathrm{m}$ silica fillers and crack-free solder joint. 


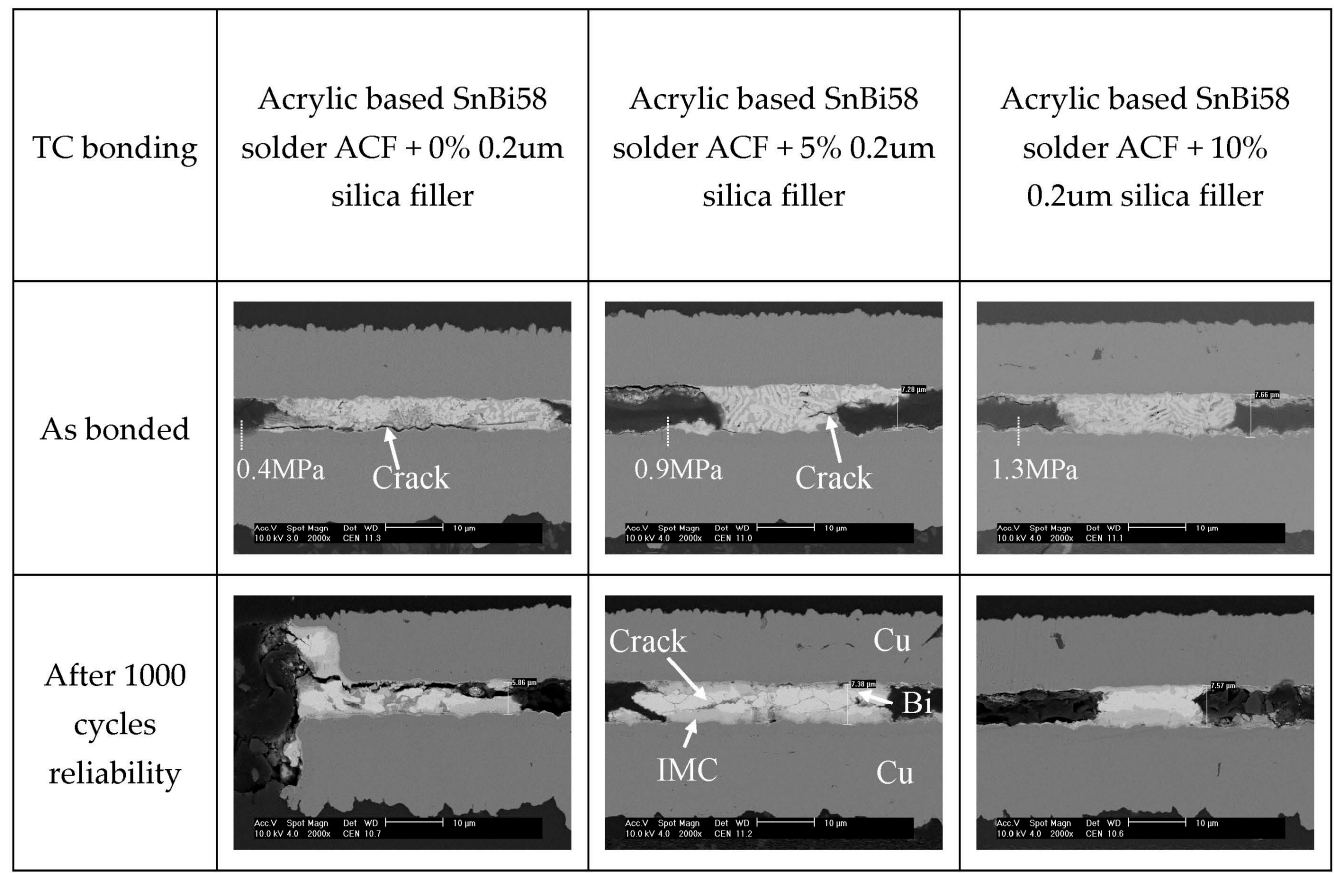

Figure 25. Solder joint morphologies of acrylic based SnBi58 solder ACFs added by 0,5 , and 10 wt $\%$ $0.2 \mu \mathrm{m}$ silica filler before and after 1000 cycles reliability test.

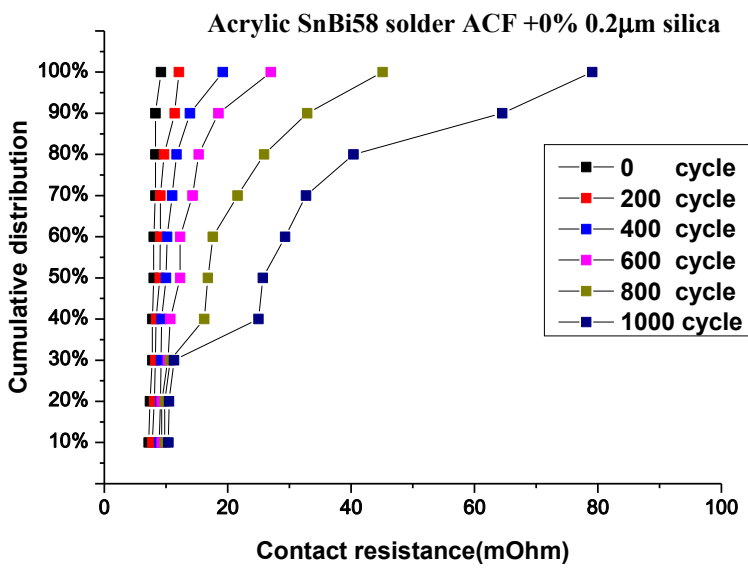

(a)

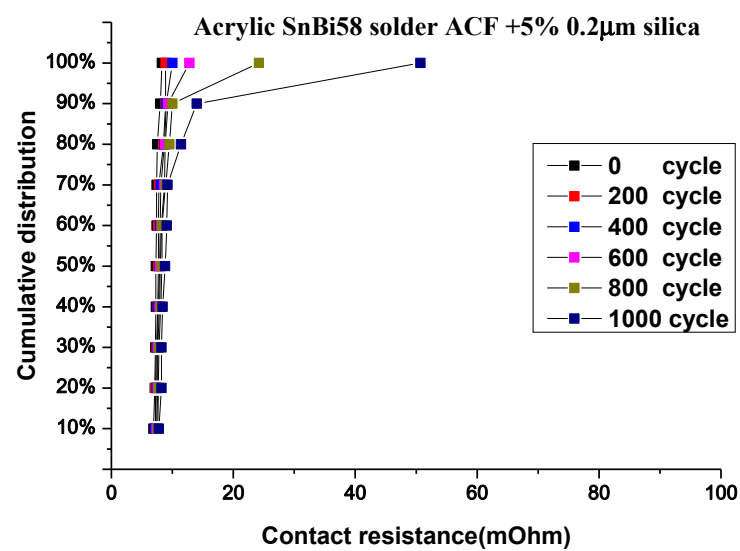

(b)

Figure 26. Cont. 


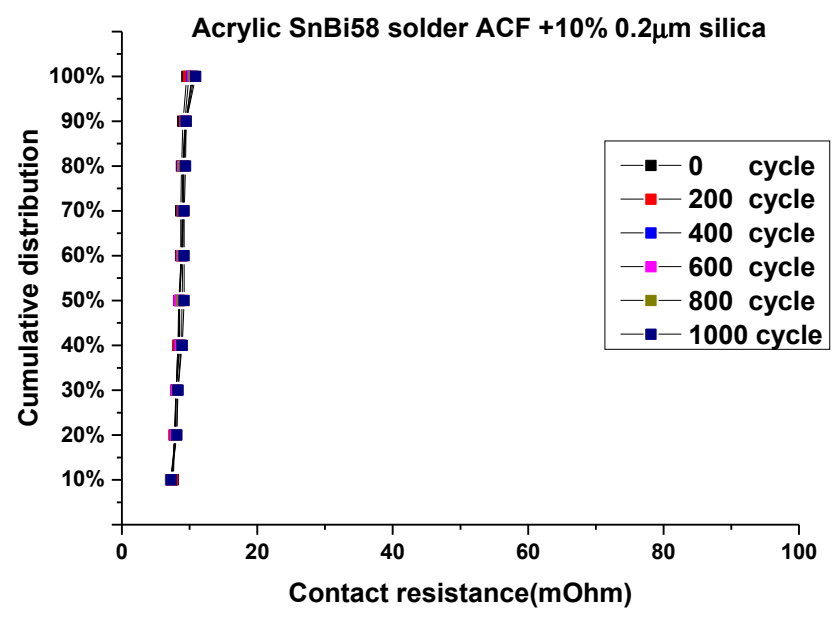

(c)

Figure 26. Solder joint contact resistances of acrylic based SnBi58 solder ACFs up to 1000 cycles T/C reliability as a function of (a) 0 , (b) 5 , and (c) $10 \mathrm{wt} \% 0.2 \mu \mathrm{m}$ silica fillers addition.

The significance of this research is to present the low resin modulus is the determined factor to cause solder joint cracks, and we provided two methods to prevent solder joint from cracking by increasing resin modulus: by delaying hot-bar lift-up time and adding Silica Fillers. The other methods, which can solve the cracks in solder joints, will be investigated and considered in future.

\section{Conclusions}

In this study, we demonstrated the storage modulus of adhesives was the key factor for solder joint morphology. Crack at solder joints occurred due to low storage modulus. Two ways were suggested to increase resin modulus to solve the solder joint cracks. The first way was to maintain bonding pressures until cooling lower than its $\operatorname{Tg}\left(45^{\circ} \mathrm{C}\right)$ during an ultrasonic bonding. The second way was to add $10 \mathrm{wt} \% 0.2 \mu \mathrm{m} \mathrm{SiO} 2$ to the low modulus acrylic ACFs solder ACFs. For ultrasonic bonding, above $5 \mathrm{MPa}$ of storage modulus was needed to prevent solder joint from cracking. However, the maintaining pressure time $70 \mathrm{~s}$ was too long for manufacturing factories over $30 \mathrm{~s}$. Using a conventional TC bonding, it was found out that resin storage modulus above $1.38 \mathrm{MPa}$ at $200{ }^{\circ} \mathrm{C}$ was needed for a crack-free SnBi58 solder joint morphology. Finally, the modified solder joint morphology was tested by a $-45 / 125^{\circ} \mathrm{C}$ reliability. After 1000 cycles, the modified solder joints showed the most stable electrical performance. Solder joint cracks can be reduced after reliability by adding $10 \mathrm{wt} \%$ $0.2 \mu \mathrm{m} \mathrm{SiO}_{2}$ fillers.

Acknowledgments: The authors thank National Natural Science Foundation of China (Grant 51474081 and 61702317) for research funding support.

Author Contributions: Shuye Zhang and Kyung-Wook Paik conceived and designed the experiments; Shuye Zhang, Mingliang Jin, Wen-Can Huang, Tiesong Lin and Peng He performed the experiments; Shuye Zhang and Panpan Lin analyzed the data; Shuye Zhang contributed reagents/materials/analysis tools; Shuye Zhang wrote the paper.

Conflicts of Interest: The authors declare no conflict of interest.

\section{References}

1. Singh, P.; Viswanadham, P. Failure Modes and Mechanisms in Electronic Packages; Springer: Berlin, Germany, 2012.

2. Kiilunen, J.; Frisk, L. Reliability analysis of an ACA attached flex-on-board assembly for industrial application. Solder. Surf. Mt. Technol. 2014, 26, 62-70. [CrossRef] 
3. Lee, K.; Saarinen, I.J.; Pykari, L.; Paik, K.W. High power and high reliability flex-on-board assembly using solder anisotropic conductive films combined with ultrasonic bonding technique. IEEE Trans. Compon. Packag. Manag. Technol. 2011, 1, 1901-1907. [CrossRef]

4. Zhang, S.; Lin, T.; He, P.; Paik, K.W. Effects of acrylic adhesives property and optimized bonding parameters on Sn 58Bi solder joint morphology for flex-on-board assembly. Microelectron. Reliab. 2017, 78, 181-189. [CrossRef]

5. Zhang, S.; Kim, S.H.; Kim, T.W.; Kim, Y.S.; Paik, K.W. A study on the solder ball size and content effects of solder ACFs for flex-on-board assembly applications using ultrasonic bonding. IEEE Trans. Compon. Packag. Manag. Technol. 2015, 5, 9-14. [CrossRef]

6. Kim, S.H.; Choi, Y.; Kim, Y.; Paik, K.W. Flux function added solder anisotropic conductive films (ACFs) for high power and fine pitch assemblies. In Proceedings of the 2013 IEEE 63rd on Electronic Components and Technology Conference (ECTC), Las Vegas, NV, USA, 28-31 May 2013; pp. 1713-1716.

7. Golla, D.F.; Hughes, P.C. Dynamics of viscoelastic structures-A time-domain, finite element formulation. ASME J. Appl. Mech. 1985, 52, 897-906. [CrossRef]

8. Zhang, S.; Paik, K.W. Effects of Cooling Processes and Silica Filler Contents of Solder ACFs (Anisotropic Conductive Films) on the Joints Reliability. In Proceedings of the 2016 IEEE 66th on Electronic Components and Technology Conference (ECTC), Las Vegas, NV, USA, 31 May-3 June 2016; pp. 737-742.

9. Ugural, A.C.; Fenster, S.K. Advanced Strength and Applied Elasticity; Pearson Education: London, UK, 2003.

10. Graffeuil, J.; Blasquez, G. Caractérisation des matériaux et des composants semiconducteurs au moyen de mesures de bruit de fond. Acta Electron. 1983, 25, 261-279.

11. Biswas, A.; Manivannan, M.; Srinivasan, M.A. Multiscale layered biomechanical model of the pacinian corpuscle. IEEE Trans. Haptics 2015, 8, 31-42. [CrossRef] [PubMed]

12. Urayama, K. An experimentalist's view of the physics of rubber elasticity. J. Polym. Sci. Polym. Phys. 2006, 44, 3440-3444. [CrossRef]

13. Van Krevelen, D.W.; Nijenhuis, K.T. Properties of Polymers; Their Correlation with Chemical Structure; Their Numerical Estimation and Prediction from Additive Group Contributions; Elsevier: Amsterdam, The Netherlands, 2009.

14. Vinogradov, G.V.; Yanovsky, Y.G.; Titkova, L.V.; Barancheeva, V.V.; Sergeenkov, S.I.; Borisenkova, E.K. Viscoelastic properties of linear polymers in the fluid state and their transition to the high-elastic state. Polym. Eng. Sci. 1980, 20, 1138-1146. [CrossRef]

15. Zhang, S.; Paik, K.W. A study on the failure mechanism and enhanced reliability of Sn58Bi solder anisotropic conductive film joints in a pressure cooker test due to polymer viscoelastic properties and hydroswelling. IEEE Trans. Compon. Packag. Manaf. Technol. 2016, 6, 216-223. [CrossRef] 